\title{
Congenital Osteofibrous Dysplasia of the Tibia: A Case Report Discovered In the Neonatal Age
}

\author{
Jalal $\mathrm{H}^{1}$, El Mortaji $\mathrm{H}^{1^{*}}$, Alami $\mathrm{Y}^{1}$, Basraoui $\mathrm{D}^{1}$, Mouhtadi $\mathrm{A}^{2}$, Elfezzazi $\mathrm{R}^{2}$
}

${ }^{1}$ Département d'imagerie Médicale, Hôpitale Mère et Enfant, CHU Med VI, Marrakech

${ }^{2}$ Département de Chirurgie infantile, Hôpital Mère et Enfant, CHU MED VI, Marrakech

DOI: $10.36347 /$ simcr.2020.v08i10.009

| Received: 20.01.2020 | Accepted: 27.01.2020 | Published: 19.10.2020

*Corresponding author: H. EL Mortaji

\section{Abstract}

Osteofibrous dysplasia is a benign and rare bone lesion which involves most often the tibia or simultaneously the tibia and the fibula bones. It is usually diagnosed during childhood or early adolescence. Although its limited evolutionary potential, it can lead to bone deformities as well as local pain. The classic radiological appearance shows zones of well-defined intracortical osteolysis as well as a curvature with an anterior apex of the diaphysis. Its evolution is characterized by a progression of the lesion and bone deformation variable during childhood then a stabilization followed by a progressive resolution in the adulthood. We report the case of an osteofibrous tibia dysplasia revealed by a deformation of the left leg in a 10-day-old female newborn.

Key words: Congenital osteofibrous dysplasia, pseudarthrosis, imaging.

Copyright $\odot 2020$ The Author(s): This is an open-access article distributed under the terms of the Creative Commons Attribution 4.0 International License (CC BY-NC 4.0) which permits unrestricted use, distribution, and reproduction in any medium for non-commercial use provided the original author and source are credited.

\section{INTRODUCTION}

Osteofibrous dysplasia is a rare disease causing osteolytic lesions, bone pain, deformities and fractures due to bone embrittlement $[1,2]$. Although it is usually diagnosed in children under the age of 12 years old, its discovery in the neonatal age remains an extremely rare situation making all the peculiarity of our case report.

\section{CaSe Report}

A 10-day-old female newborn presented to our department with a deformity of the left leg. The radiographic assessments showed a metaphysodiaphyseal osteolysis of the proximal tibia, blowing the cortical bone witch is ruptured and complicated by a pathological fracture with pseudarthrosis signs (Figure 1). The CT scan revealed a lytic mass within the metaphysis and diaphysis parts of the proximal tibia. A frosted glass appearance of the bone was associated and responsible for a rupture of the cortical bone (Figure 2). The diagnosis of congenital osteo-fibrous dysplasia of the tibia was mentioned and then confirmed by the anatomopathological assessment carried out on the biopsy cores. For the treatment, the tumor was removed surgically and filled with a bone graft (auto graft). The radiographic control showed the initiated ossification and consolidation of the bone lesion (Figure 3).

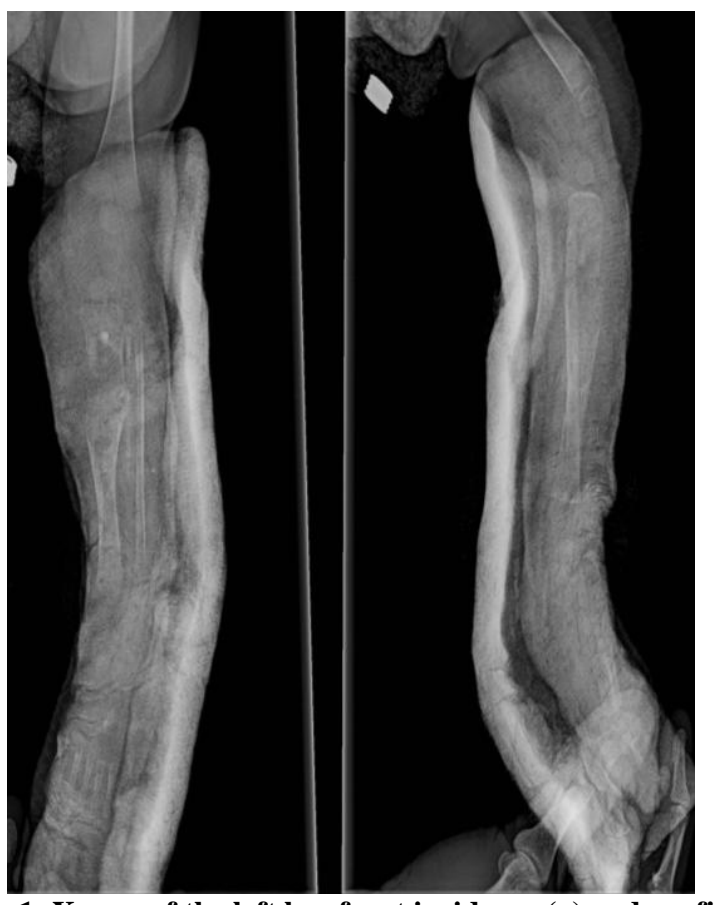

Fig-1: X-rays of the left leg, front incidence (a) and profile (b) showing an osteolysis of the metaphysis and diaphysis of the proximal tibia, with a geographic shape, responsible for a thinning and rupture of the cortex with no associated periosteal reaction, complicated by a fracture and pseudarthrosis 

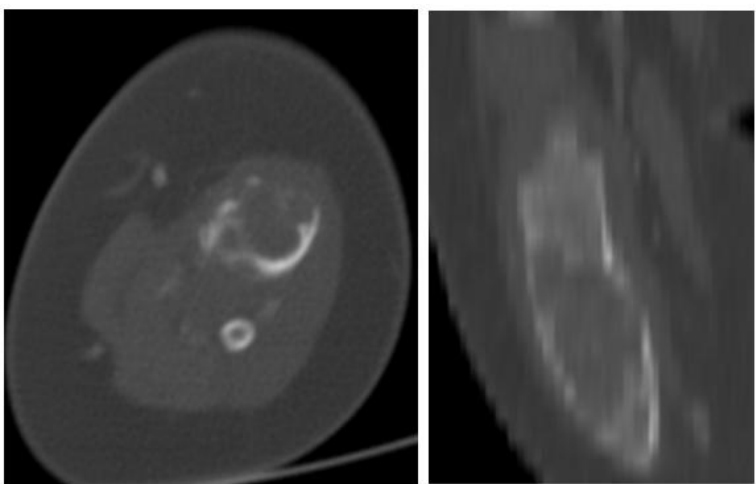

Fig-2: Axial (a) and coronal (b) CT images showing an osteolytic metaphyseal and dyaphyseal mass of the proximal left tibia. A frosted glass appearance of the bone is associated and responsible for a rupture of the cortical bone
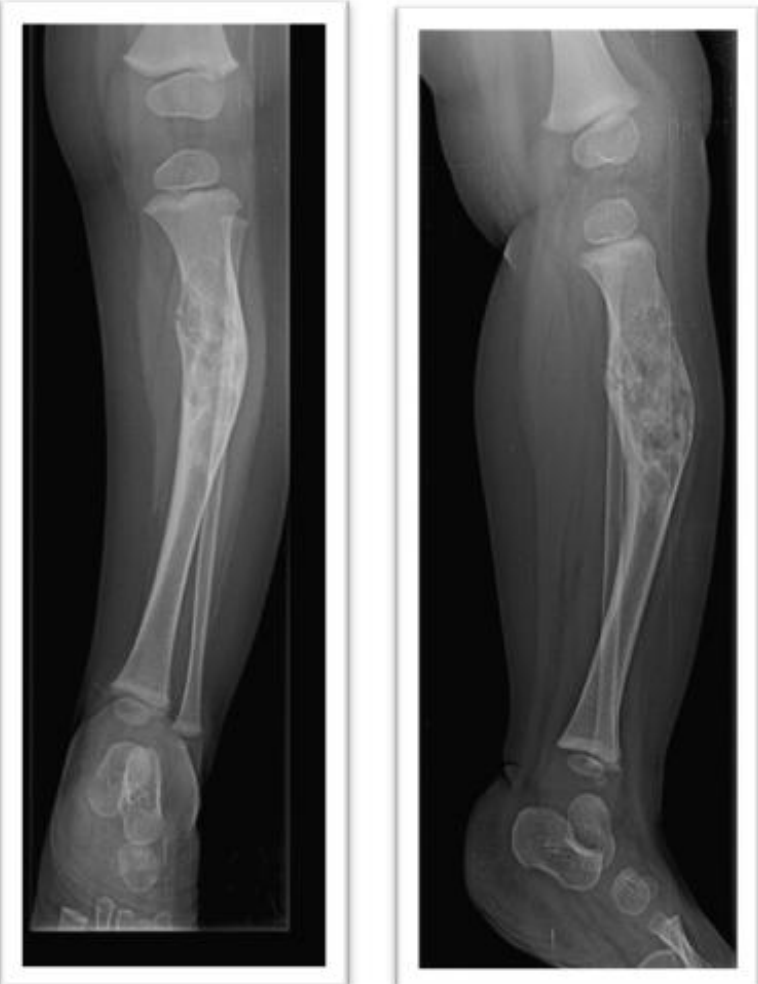

Fig-3: Radiographic control carried out after surgery with front (a) and profile (b) views showing the ossification and the initiated consolidation with the persistance of a deformity of the bone

\section{DISCUSSION}

Osteofibrous dysplasia of long bones is a rare bone lesion of an unknown pathogenesis, first described as a separate entity by Campanacci in 1976. It is an intracortical lesion which occures almost exclusively in the tibia or fibula in childs under the age of 10 [3].

Its incidence is estimated at $0.2 \%$ of all primary bone tumors. There is a slight preponderance in the male subjects. The disease is usually diagnosed before the age of 20 and most often in young people under 12 yers old [4].
The lesion is usually located at the diaphysis of the tibial bone associated sometimes with a damage of the adjacent fibula. Rarely, the fibula is affected isolatedly. The location within the the radius or ulna bones is a phenomenon rarely described [5].

Usually, the main symptom is a curvature or swelling caused by the thickening of the tibia. Osteofibrous dysplasia can be revealed by pain witch is the result of a crack, a pathological fracture, a bone deformation with functional handicap or a secondary arthrosis $[6,7]$. Congenital presentation is exceptional and could be associated with pseudarthrosis [8] as is the case reported.

The diagnosis is evoked by radiological findings. These will highlight an osteolytic lesion, often heterogeneous, with a thinned cortex, with sometimes an enlarged bone with a peripheral osteocondensation. Radiographic exams can also reveal a "Frosted glass" appearance of the bone wich is highly suggestive of the diagnosis [7]. The preferred sites are the diaphysis of the long bones, the metaphyses of the femoral neck in particular, the ribs, the spine and the cranio-facial bones. CT can assess the risk of fracture, by measuring the thickness of the cortical bone. It can also identify invisible cracks on standard radiographics [4].

On MRI, osteofibrous dysplasia, like most bone tumors, demonstrates an intermediate or weak signal in $\mathrm{T} 1$ weighted images and an intense signal in T2 sequences. A moderate and homogeneous enhancement can be noted. Magnetic resonance imaging is particularly useful for demonstrating the intramedullary extension of the tumor, its relationships with surrounding tissues, and for the detection of multiple locations that are sometimes unsuspected in simple radiographs [9].

Histologically, osteofibrous dysplasia is characterized by the presence of a fibrous and osteogenic matrix with evidence of a small portion of epidermoid cells on the immunohichemical tests. The presence of islands of epithelial cells on the basic stains must be associated with a diagnosis of a differentiated adamantinoma [4].

The range of differential diagnoses of osteofibrous dysplasia is potentially wide. It includes any osteolytic lesion affecting the cortical bone of a child or young adult whether benign or malignant. In addition to the adamantinoma, we must consider histiocytic fibroma, fibrous dysplasia, aneurysmal bone cysts, chondromyxoid fibroma, eosinophilic granuloma, osteomyelitis, osteosarcoma and hemangioendothelioma or angiosarcoma $[10,11]$. However, careful review of the patient's clinical informations, including age, medical history, physical examination, site of injury, and data from radiological examinations is very helpful to reduce the range of the 
differential diagnosis. However, it is still more difficult to differentiate osteofibrous dysplasia from adamantinoma in its differentiated form because of their matching clinico-radiological and histopathological characteristics [10].

Osteofibrous dysplasia is a benign and non agressive lesion that does not progress after puberty. The main purpose of the therapeutic approach is to control the activity of the disease, reduce pain, prevent complications and improve the life quality of patients. Surgery is generally limited to extensive or very deforming lesions and pseudarthrosis. Those situations appear to be rare $[6,10]$.

\section{CONCLUSION}

Osteofibrous dysplasia of the long bones is a rare and benign bone lesion, usually occurring in children and often affecting the tibia and fibula bones. Its discovery in the neonatal age is an extremely rare situation. Imaging features are very helpful for the diagnosis and the follow-up. The anatomopathological study is mandatory to make the differential diagnosis with other pathologies.

\section{REFERENCES}

1. Campbell CJ, Hawk T. A variant of fibrous dysplasia (osteofibrous dysplasia). The Journal of bone and joint surgery. American volume. 1982 Feb;64(2):231-6.

2. Coley BL. Neoplasms of bone and related conditions: etiology, pathogenesis, diagnosis, and treatment. Hoeber; 1960.

3. Campanacci M. Osteofibrous dysplasia of long bones a new clinical entity. Italian journal of orthopaedics and traumatology. 1976 Aug;2(2):221-37.

4. Khanna M, Delaney D, Tirabosco R, Saifuddin A. Osteofibrous dysplasia, osteofibrous dysplasia-like adamantinoma and adamantinoma: correlation of radiological imaging features with surgical histology and assessment of the use of radiology in contributing to needle biopsy diagnosis. Skeletal radiology. 2008 Dec 1;37(12):1077.

5. Wang JW, Shih CH, Chen WJ. Osteofibrous dysplasia (ossifying fibroma of long bones). A report of four cases and review of the literature. Clinical orthopaedics and related research. 1992 $\operatorname{May}(278): 235-43$.

6. Gleason BC, Liegl-Atzwanger B, Kozakewich HP, Connolly S, Gebhardt MC, Fletcher JA, PerezAtayde AR. Osteofibrous dysplasia and adamantinoma in children and adolescents: a clinicopathologic reappraisal. The American journal of surgical pathology. 2008 Mar 1;32(3):363-76.

7. Teo HE, Peh WC, Akhilesh M, Tan SB, Ishida T. Congenital osteofibrous dysplasia associated with pseudoarthrosis of the tibia and fibula. Skeletal radiology. 2007 Jun 1;36(1):7-14.

8. Sarisozen B, Ozturk C, Yazici Z, Ozturk H. Neonatal osteofibrous dysplasia: a case report. European Journal of Orthopaedic Surgery \& Traumatology. 2005 Mar 1;15(1):57-9.

9. Jung JY, Jee WH, Hong SH, Kang HS, Chung HW, Ryu KN, Kim JY, Im SA, Park JM, Sung MS, Lee YS. MR findings of the osteofibrous dysplasia. Korean journal of radiology. 2014 Feb 1;15(1):11422.

10. Most MJ, Sim FH, Inwards CY. Osteofibrous dysplasia and adamantinoma. JAAOS-Journal of the American Academy of Orthopaedic Surgeons. 2010 Jun 1;18(6):358-66.

11. Papagelopoulos PJ, Mavrogenis AF, Galanis EC, Savvidou OD, Inwards CY, Sim FH. Clinicopathological features, diagnosis, and treatment of adamantinoma of the long bones. Orthopedics. 2007 Mar 1;30(3):211-5. 